\title{
An exploration study to detect important factors influencing on development of RFID in after sales services
}

\author{
Gholamreza Hashemzadeh, Ali Namkin and Mohammad Hassani*
}

Department of Management and Accounting. Tehran South Branch. Islamic Azad Universitv. Tehran, Iran

\begin{tabular}{|c|c|}
\hline CHRON I C LE & ABSTRACT \\
\hline $\begin{array}{l}\text { Article history: } \\
\text { Received January 20, } 2014 \\
\text { Accepted } 30 \text { August } 2014 \\
\text { Available online } \\
\text { August } 302014 \\
\text { RFID } \\
\text { Factor analysis } \\
\text { Auto industry }\end{array}$ & $\begin{array}{l}\text { Radio-frequency identification (RFID) is the wireless use of electromagnetic fields to transfer } \\
\text { necessary information, for the purposes of automatically identifying and tracking tags attached } \\
\text { to various objects. This paper presents a survey to study the role of different factors influencing } \\
\text { on RFID implementation in after sales services in auto industry. The study designs a } \\
\text { questionnaire and distributes it among } 20 \text { managers who work for after sales services in auto } \\
\text { industry located in city of Tehran, Iran. Cronbach alpha has been calculated as } 0.74 \text {, which is } \\
\text { well above the minimum acceptable level. Using the existing literature as well as a survey with } \\
\text { experts, the study has detected four important factors including management, technical, } \\
\text { economic and environmental factors. We also weight all factors and sub-factors using Shannon } \\
\text { entropy method. }\end{array}$ \\
\hline
\end{tabular}

\section{Introduction}

Radio-frequency identification (RFID) is the wireless use of electromagnetic fields to transfer necessary information, for the purposes of automatically identifying and tracking tags attached to various objects. Konsynski and Smith (2003) summarized the ways in which firms and academics were thinking about RFID technologies and stimulated strategic thinking about their possible implications. There are literally various studies on the effects of RFID implementation for business development. Fosso Wamba et al. (2008) presented application of RFID for business to business development in retail industry. They concluded that RFID implementation could improve supply chain management. Attaran (2007) introduced RFID as an enabler of supply chain management. Janz et al. (2005) discussed different successful implementation of RFID for health care industry. Li et al. (2005) discussed different applications of mobile RFID for health care purposes.

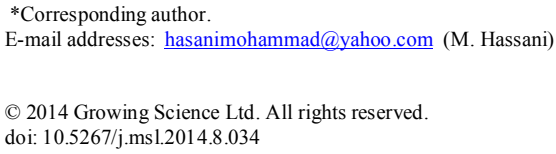




\section{The proposed study}

This paper presents a survey to study the role of different factors influencing on RFID implementation in after sales services. The study designs a questionnaire and distributes it among 20 managers who work for after sales services in auto industry located in city of Tehran, Iran.

\subsection{Shannon entropy and objective weights}

Shannon (2001) proposed the entropy concept, which is a measure of uncertainty in information formulated in terms of probability theory. The entropy concept is well suited for measuring the relative contrast intensities of criteria to demonstrate the average intrinsic information transmitted to the decision maker (Zeleny, 1982).

\subsection{Entropy weighting method}

The entropy weighting method (Zeleny, 1982) can effectively measure the average essence of data quantity, and the larger the entropy value, the lower the information express quantity (Zeleny, 1982, Feng \& Chen, 1992). The steps of the algorithm can be summarized as follows:

Step 1. Let $x_{i j}, \mathrm{i}=1,2, \ldots, \mathrm{m} ; \mathrm{j}=1,2, \ldots, \mathrm{n}$, be the superiority rating of the $\mathrm{i}^{\text {th }}$ alternative under $\mathrm{j}^{\text {th }}$ criterion above the alternative level. Then we can define

$$
X=\left[x_{i j}\right]_{m \times n} \quad i=1, \ldots, m, j=1, \ldots, n
$$

and we call $X$ as decision matrix.

Step 2. Form normal decision matrix $R=\left[r_{i j}\right]_{m \times n}$, where

$$
\forall i, j, r_{i j}=\frac{x_{i j}}{\sum_{i=1}^{m} x_{i j}}
$$

Step 3. Calculation of concentration index for per criteria's data as follows,

$$
E_{j}=-\frac{1}{\ln (m)} \sum_{i=1}^{m} r_{i j} \ln \left(r_{i j}\right), j=1, \ldots, n
$$

In Eq. (3), lower value for $E_{j}$ implies less concentration of data $C_{j}$ criteria and more dispersal of its data.

Step 4. Determination the amount of per criteria's Dispersal

The amount of per criteria's Dispersal calculated as follows,

$$
d_{j}=1-E_{j} \quad j=1, \ldots, n
$$

Step 5. Calculation the weight of criteria:

The weights of criteria calculated are as follows:

$$
W_{j}=\frac{d_{j}}{\sum_{j=1}^{n} d_{j}} \quad j=1, \ldots, n
$$

Therefore, we have, $0 \leq w_{j} \leq 1, j=1, \cdots, 1$. 


\section{The results}

The proposed study of this paper uses the existing literatire as well as brain storming with some experts has derived some important factors summarized in Table 1 as follows,

\section{Table 1}

The summary of factors on the effect of RFID for business development in auto industry

\begin{tabular}{clll}
\hline Item & Attribute & Sub-factor & DM/Literature \\
\hline 1 & & The relationship of executive managers with top management & Decision maker \\
2 & & Reasonable expectation from RFID & Decision maker \\
3 & \multirow{4}{*}{ Management } & Zeleny, 1982 \\
4 & Coordination of team with levels of management team & Decision maker \\
5 & & Credibility of executable team & Decision maker \\
6 & & The rate involvement of all employees & Gibbs \& Kraemer, 2004 \\
7 & & Management of customers' information & Decision maker \\
\hline 8 & & Management interest in RFID development & Gibbs \& Kraemer, 2004 \\
9 & & Financial affordability for paying RFID investment & Gibbs \& Kraemer, 2004 \\
10 & Economic & Financial support on behalf of managing director & Decision maker \\
11 & & Necessary budget allocation & Decision maker \\
12 & & Cost reduction in operations & Ozturk \& Palakurthi, 2010 \\
\hline 13 & Feasibility study for RFID implementation & Shin - Yuan Hung, 2010 \\
14 & & Existence of necessary technical knowledge & Yu Min Wang, 2010 \\
15 & & Business knowledge & Decision maker \\
16 & & Technical skills & Brown \& Russell, 2007 \\
17 & Technical & Technical supervision & Decision maker \\
18 & & Using technical supportive experts on RFID & Decision maker \\
19 & Having appropriate technical knowledge & Shih et al., 2008 \\
20 & & Compatibility of the system with infrastructure & Decision maker \\
21 & & Availability of supportive teams & Brown \& Russell, 2007 \\
\hline 22 & & Maturity of RFID technique in after sales services & Decision maker \\
23 & & Organizational culture & Zhang et al., 2007 \\
24 & & Existing infrastructures & Shih et al., 2008 \\
25 & Environmental & Decision maker \\
26 & Coordination of RFID with organizational strategy & Decision maker \\
27 & Compatibility of RFID system with previous technology & Decision maker \\
29 & Maturity of organization on coping with RFID & Decision maker \\
\hline & Risk identification and assessment & Gibbs \& Kraemer, 2004; Zhang et al ,2007 \\
\hline
\end{tabular}

As we can observe from the results of Table 1, there are 29 items associated with the proposed study of this paper. We have further discussed the items and managed to reduce the number of items, accordingly. In addition, Table 2 shows details of our rankings for sub-factors.

Table 2

The summary of ranking for sub-factors

\begin{tabular}{|c|c|c|c|c|c|}
\hline Rank & $\begin{array}{l}\text { Sub-criteira } \\
\end{array}$ & Criteria & $W_{j}$ & $E_{j}$ & $D_{j}$ \\
\hline 1 & Coordination of RFID with organizational strategy & Environmental & 0.0508 & -2.61716 & 3.617158 \\
\hline \multirow[b]{2}{*}{2} & Budget & Economic & \multirow{2}{*}{0.0507} & \multirow{2}{*}{-2.60785} & \multirow{2}{*}{3.607848} \\
\hline & Willing for execution & Management & & & \\
\hline 3 & Organizational culture & Environmental & 0.0506 & -2.6046 & 3.604602 \\
\hline \multirow{2}{*}{4} & Technological maturity & Technical & \multirow{2}{*}{0.0505} & \multirow{2}{*}{-2.59845} & \multirow{2}{*}{3.598451} \\
\hline & Financial support & Economic & & & \\
\hline \multirow{2}{*}{5} & Technological agreement & Environmental & \multirow{2}{*}{0.0502} & \multirow{2}{*}{-2.58189} & \multirow[b]{2}{*}{3.581892} \\
\hline & Financial affordability & Economic & & & \\
\hline \multirow{3}{*}{6} & Risk assessment & Environmental & \multirow{3}{*}{0.05} & \multirow{3}{*}{-2.57111} & \multirow{3}{*}{3.571114} \\
\hline & Compatibility with standards & Environmental & & & \\
\hline & Management relationships & Management & & & \\
\hline \multirow{2}{*}{7} & Guarantee & Technical & \multirow{2}{*}{0.0499} & \multirow{2}{*}{-2.56745} & \multirow{2}{*}{3.567446} \\
\hline & Economic fusibility & Economic & & & \\
\hline \multirow{2}{*}{8} & Expert consultant & Technical & \multirow{2}{*}{0.0498} & \multirow{2}{*}{-2.56502} & \multirow{2}{*}{3.565019} \\
\hline & Economic value & Economic & & & \\
\hline 9 & Coordination & Management & 0.0495 & -2.54996 & 3.549959 \\
\hline 10 & Involvement & Management & 0.0494 & -2.54262 & 3.542616 \\
\hline \multirow{2}{*}{11} & Coordination & Technical & \multirow{2}{*}{0.0492} & \multirow{2}{*}{-2.52993} & \multirow{2}{*}{3.529932} \\
\hline & Maintenance knowledge & Technical & & & \\
\hline 12 & Reputation & Management & 0.0491 & -2.52724 & 3.527242 \\
\hline
\end{tabular}




\section{Discussion and conclusion}

The implementation of Entropy weighting method for four major attributes of management, economic, technical and environmental yields $0.2487,0.2511,0.2486$ and 0.2516 , respectively. As we can observe from the results of Table 2, Coordination of RFID with organizational strategy as an environmental factor is number one priority followed by the availability of necessary budget as well as management team's willingness on execution of such project. Organizational culture is the third important factor, which plays essential role for the development of RFID in after sales services. In addition, technological maturity and financial affordability are other important factors, which could help for the RFID development. In terms of environmental factors, having a good risk assessment and compatibility with existing standards are another important factors for the proposed study of this paper while building a good relationship with customers is another important management factor. The results of our survey are somewhat consistent with the results of Ozturk and Palakurthi (2010), Brown and Russell (2007) and Shih et al. (2008).

\section{References}

Attaran, M. (2007). RFID: an enabler of supply chain operations. Supply Chain Management: An International Journal, 12(4), 249-257.

Brown, I., \& Russell, J. (2007). Radio frequency identification technology: An exploratory study on adoption in the South African retail sector. International Journal of Information Management, 27(4), 250-265.

Feng, C. M., \& Chen, C. F. (1992). The determination of criteria weights-compromised weighting method. Traffic and Transportation, 14, 51-67.

Fosso Wamba, S., Lefebvre, L. A., Bendavid, Y., \& Lefebvre, É. (2008). Exploring the impact of RFID technology and the EPC network on mobile B2B eCommerce: A case study in the retail industry. International Journal of Production Economics, 112(2), 614-629.

Gibbs, J. L., \& Kraemer, K. L. (2004). A cross-country investigation of the determinants of scope of E-commerce use: An institutional approach. Electronic Markets, 14(2), 124-137.

Janz, B. D., Pitts, M. G., \& Otondo, R. F. (2005). Information systems and health care-II: Back to the future with RFID: Lessons learned-some old, some new. Communications of the Association for Information Systems, 15(1), 7.

Li, C. J., Liu, L., Chen, S. Z., Wu, C. C., Huang, C. H., \& Chen, X. M. (2004). Mobile healthcare service system using RFID. In Networking, Sensing and Control, 2004 IEEE International Conference on (Vol. 2, pp. 1014-1019). IEEE.

Ozturk, A., \& Palakurthi, R. (2010). Factors affecting customer's intention to use RFID technology in the hotel industry. Proceedings of the 15th Annual Graduate Student Research Conference on Hospitality and Tourism, 50-60.

Konsynski, B., \& Smith, H. A. (2003). Developments in practice x: Radio frequency identification (rfid)-an internet for physical objects. Communications of the Association for Information Systems, 12(1), 19.

Shannon, C. E. (2001). A mathematical theory of communication. ACM SIGMOBILE Mobile Computing and Communications Review, 5(1), 3-55.

Shih, D. H., Chiu, Y. W., Chang, S. I., \& Yen, D. C. (2008). An empirical study of factors affecting RFID's adoption in Taiwan. Journal of Global Information Management (JGIM), 16(2), 58-80.

Zeleny, M. (1982). Multiple criteria decision making (Vol. 25). J. L. Cochrane (Ed.). New York: McGraw-Hill. 